\title{
A Comparative Assessment of Dry Eye Disease Among Outdoor Street Sweepers and Indoor Office Cleaners
}

\section{Chigozie Ifeoma Echieh}

University of Calabar Teaching Hospital

\section{Bassey A Etim}

University of Calabar

Chidiebere Peter Echieh ( $\nabla$ cechieh@unical.edu.ng)

University of Calabar https://orcid.org/0000-0002-0472-7894

Jeff Ajewole

University of Calabar Teaching Hospital

Research article

Keywords: Dry eye disease; Ocular surface disorder, occupational health

Posted Date: May 5th, 2020

DOI: https://doi.org/10.21203/rs.3.rs-20627/v1

License: (c) This work is licensed under a Creative Commons Attribution 4.0 International License.

Read Full License

Version of Record: A version of this preprint was published at BMC Ophthalmology on June 26th, 2021. See the published version at https://doi.org/10.1186/s12886-021-02025-y. 


\section{Abstract}

\section{Background:}

Occupational predisposition to dry eye disease is known. Simultaneous exposure to multiple factors may pose more risk. Street sweepers are exposed to sunlight in addition to dust which all sweepers are exposed to. This study aims to assess the prevalence of dry eye disease (DED) amongst Street sweepers and Office cleaners in Calabar metropolis.

\section{Methods:}

A cross sectional study was conducted among street sweepers and office cleaners. A systematic random sampling and multi-stage sampling method was used to select street sweepers $(n=115)$ and office cleaners $(n=115)$ respectively for the study. A pretested semi-structured interviewer administered questionnaire was used to obtain information after which the respondents had an ophthalmic examination. An assessment of DED was done with Ocular Surface Disease Index (OSDI) questionnaire, Schirmer's test and tear break up time (TBUT).

\section{Results:}

Majority of respondents were females 215(93.5\%) compared to males $15(6.5 \%)$. The overall mean age of respondents was $40.96 \pm 9.8$ years. The prevalence of DED among Street sweepers was $35.7 \%$ compared to $20 \%$ among office cleaners using the OSDI questionnaire. The prevalence of DED among street sweepers was $32.2 \%$ compared to $30.4 \%$ among Office cleaners using the Schirmer's test. The TBUT reported a prevalence of $38.3 \%$ of DED among Street sweepers compared to $32.2 \%$ in Office cleaners.

\section{Conclusion:}

This study concluded that street sweepers had higher odds of developing dry eye disease compared to office cleaners. This effect is possibly due to synergy of factors. Studies on dose response are warranted. Strict use of protective gears that protect from multiple risk factors are recommended.

\section{Background}

The ocular surface is a sensitive structure that includes the conjunctiva and cornea bordered by the upper and lower lids and covered by a thin layer of tear film. ${ }^{1}$ Its main function is to enable clear vision in an open eye by contributing more than two-thirds of the total refractive power of the eye. ${ }^{2}$ All parts of this surface are directly exposed to the external environment and are thus vulnerable to potential environmental insults. ${ }^{3}$

Ocular surface disorder (OSD), a broad term encompassing Dry Eye Disease (DED), blepharitis and meibomian gland dysfunction, allergic eye disease as well as chemical and thermal burns; may result in decreased visual function and poor performance of workers. ${ }^{4}$ Impaired visual function has been shown 
to be an important factor that can adversely affect job output and quality. ${ }^{5,6}$ For example, Nichols et al reported that dry eye causes negligible absenteeism but markedly reduces workplace performance, and that impairment of workplace performance is more closely related to dry eye symptoms than to clinical signs. 5

Dry eye disease is an ocular surface disease, characterized by a disorder of the tear film resulting from tear deficiency or excessive evaporation which causes damage to the inter- palpebral ocular surface and is associated with symptoms of ocular discomfort. ${ }^{7}$ The prevalence of dry eye disease ranges from 5$35 \%$ worldwide, in Nigeria it is at $19.2 \%$ based on the ocular surface disease index data. ${ }^{8,9}$ Environmental factors play an important role in the etiology of dry eye disease. ${ }^{10}$ Surface toxicity, oxidative stress and inflammation are the mechanisms implicated. ${ }^{11}$ Occupational predisposition resulting from sunlight and dust exposure in outdoor workers as well as prolonged use of computers among professionals are risk factors for developing dry eye disease. ${ }^{12}$ Most of these factors have been studied singly.

We hypothesize that working outdoors in the presence of sunlight and dust (as typified by street sweepers in Calabar) may be associated with greater prevalence of dry eyes compared with working indoors in the presence of dust but absence of direct sunlight (as typified by indoor cleaners). The aim of this was to determine and compare the prevalence of dry eye disease among street sweepers who work outdoors and indoor office cleaners in Calabar metropolis, Nigeria.

\section{Methods}

In this cross-sectional study, 230 respondents were involved in the study. A systematic random technique was used to recruit one hundred and fifteen (115) street sweepers from the Calabar Urban Development authority (CUDA), an agency responsible for maintaining environmental sanitation in the metropolis. On the other hand, one hundred and fifteen (115) office cleaners were recruited from 5 out of 28 ministries in the metropolis using a multi-stage sampling technique. Ethical approval was obtained from the Health Research Ethical Committee of University of Calabar Teaching Hospital before commencing the study.

The sample size was determined using the formula for comparison of two proportions. Average prevalence of ocular surface disorders among exposed workers $\left(P_{1}=14.0 \%\right)$ and average prevalence of ocular surface disorders among unexposed workers $\left(P_{2}=3.125 \%\right)$ from previous study ${ }^{13}$ conducted in Benin, Nigeria was used in the calculation. To take care attrition, $10 \%$ of the calculated sample size was added. One hundred and fifteen subjects each, were recruited into the indoor sweepers and outdoor sweepers arms respectively, totaling 230 subjects.

A written informed consent was obtained from the respondents and an interviewer administered questionnaire (see supplementary file) was used to obtain data on socio-demographics, work history, ocular surface disease index and ocular symptoms. All respondents underwent an ocular examination where dry eye disease was assessed using Schirmer's 1 test and tear film break up time. 
Schirmer's 1 test value of $10 \mathrm{~mm}$ in $5 \mathrm{mins}$ on Whatman's filter paper no. 41, and a-Tear film break up time (TBUT) value of $<10$ seconds was used as a cut-off mark for assessing dry eye disease.

Statistical analysis was performed using SPSS software version 20. A P value of $<0.05$ was considered statistically significant. The prevalence odds ratio was used to study the strength of the association of occupational risk factors (street sweepers and office cleaners) with dry eye disease.

\section{Results}

Overall, 230 respondents participated in the study. Fifty per cent $(50.0 \%)$ were outdoor street sweepers while the remaining $50.0 \%$ were indoor office cleaners. Female: male ratio was $1: 0.03$. Over half of the respondents $(51.3 \%)$ were aged 40 years and below with a mean age of $40 \pm 9.6$ years.

The mean age of the outside street sweepers was $41.78 \pm 10.39$ years while that of the office cleaners was $40.26 \pm 9.46$ years (Table 1 ). There was no statistically significant difference between the mean ages of the different group of workers $(t=1.187, p=0.155)$ Slightly less than one-third $(31.7 \%)$ of the respondents had been educated up to primary school level.

\section{Prevalence of dry eye disease using OSDI, Schirmer's Test 1, TBUT}

Overall, dry eye disease was found in 64 of the 230 respondents assessed, giving a prevalence of $27.8 \%$ using the ocular surface disease index (Fig. 1). Results obtained from the OSDI ranged from 0-78, with a mean score of $26.4 \pm 16.0$.

Overall, the prevalence of dry eye disease assessed by Schirmer's test was 31.3\% (Fig. 1). Out of 230 respondents, 72 had abnormal Schirmer's test. Results obtained from Schirmer's test ranged $1 \mathrm{~mm}$ to $35 \mathrm{~mm}$ with a mean of $16.44 \pm 9.52$.

The overall prevalence of dry eye disease assessed using the TBUT among street sweepers and office cleaners was $35.2 \% .81$ respondents out of 230 had abnormal TBUT. Results obtained from the TBUT ranged between 2 seconds to 35 seconds, with a mean of $12.12 \pm 4.28$.

\section{Comparing prevalence of dry eye disease in street sweepers and office cleaners using OSDI}

Dry eye disease was found in 41 out of 115 street sweepers giving a prevalence of $35.7 \%$ (Fig. 2). On the other hand, dry eye disease was found in 23 out of 115 office cleaners resulting in a prevalence of $20 \%$. This difference was not statistically significant ( $p$ value 0.352 ).

\section{Comparing prevalence of Dry Eye disease in street sweepers and office cleaners using Schirmer's test}

Comparing the prevalence of dry eye disease diagnosed using Schirmer's test in street sweepers and office cleaners showed that 37(32.2\%) out of 115 street sweepers had abnormal Schirmer's test compared to 35 (30.4\%) of 115 office cleaners (Fig. 3). The prevalence was higher in street sweepers compared to office cleaners. However, this difference was not statistically significant ( $p$ value $=0.73$ ). 


\section{Comparing prevalence of dry eye disease using TBUT in street sweepers and office cleaners}

Assessment of dry eye disease using TBUT shows that, out of 115 street sweepers, 44 had abnormal TBUT giving a prevalence of $38.3 \%$ (Fig. 4). On the other hand, of the 115 office cleaners, 37 had abnormal TBUT giving a prevalence of $32.2 \%$. This difference was however not statistically significant ( $p$ value $=0.48)$.

\section{Relationship between risk factors and the occurrence of dry eye disease}

Logistic regression was performed to assess the impact of statistically significant factors on the likelihood of developing dry eye disease. As shown in the Table 2, the class of workers and ages of respondents had a statistically significant contribution to the occurrence of dry eye disease.

The result demonstrates that street sweepers were more likely to develop a dry eye disease compared to office sweepers with an odds ratio of 2.085 (Table 3). Another predictor observed in this study for developing dry eye disease was the age of respondents in years with a prevalence odds ratio of 1.092 . This indicates that increasing age of respondents in years is a weak predictor of the occurrence of dry eye disease.

\section{Discussion}

Documented prevalence of dry eye disease among workers is diverse, this study sought to determine the prevalence of dry eye disease among street sweepers who are outdoor workers and office cleaners who work predominantly indoors. Both populations work in dusty environments however; street sweepers, in addition are exposed to direct sunlight

The prevalence of dry eye disease assessed subjectively using the ocular surface disease index questionnaire (OSDI) among all respondents was $27.8 \%$. In addition, this study noted a prevalence of $31.4 \%$ and $35.3 \%$ respectively based on Schirmer's test 1 and tear break up time (TBUT) respectively (Fig. 1). This study showed a higher prevalence of dry eye disease in street sweepers compared to office cleaners with the varied clinical tests. This finding could be explained by the fact that street sweepers are slightly more symptomatic as a result of continuous and long term sweeping which exposes them more to environmental irritants such as dust and smoke. The prevalence rate in this study is higher than that reported in South East Nigeria (19.2\%) using the OSDI questionnaire. ${ }^{9}$ The results of this study are comparable with other studies conducted among outdoor workers where the prevalence of dry eyes disease was higher amongst outdoor workers compared with indoor workers. ${ }^{14,15}$ Our study showed a higher prevalence of dry eye disease in Street sweepers compared to office cleaners using the OSDI, Schirmer's test and Tear Break up time respectively.(Figs. 2, 3, 4). Suchi et al reported a prevalence of $59.3 \%$ of dry eyes among outdoor jobs consisting of farmers and labourers and a prevalence of $42.6 \%$ in indoor jobs. ${ }^{14}$ Khurana et al, reported an increased risk of dry eye among farmers and laborers $(32 \%$ and $28 \%$ respectively and attributed this increase to excessive exposure of these workers to adverse environmental conditions. ${ }^{15}$ 
The ocular complaints among participants in this study were itching, redness of the eyes, foreign body sensation, and tearing, ocular pain and mucoid discharge. (Table 4) This may result from a disturbance of the ocular surface where sand dust acts as direct irritants to the eyes. This corroborates with the study performed in Australia by McCarty et al who reported that most of the patients with dry eyes presented with the symptoms of foreign body sensation, itching tearing and photophobia. ${ }^{16}$

This study noted that street sweepers were twice more likely to develop dry eye disease compared to office sweepers with an odds ratio of 2.085. (Table 3) Furthermore, dry eye disease was noted to be associated with the age of the workers, with increasing age, a worker was more likely to develop dry eye disease (Table 2). This finding corroborates an earlier study that noted dry eye disease to be significantly associated with increasing age. ${ }^{17}$

The findings from our study further highlights the increased risk of developing dry eye disease in outdoor workers (street sweepers) constantly exposed to combined environmental irritants like dust and sunlight. The increased burden on street sweepers is likely to be due to synergistic effect of irritants. A dose relationship between burden of dry eyes and exposure to irritant(s) warrants further studies. Earlier studies on this subject ${ }^{18}$ documented a high level of awareness on ocular health safety among street sweepers however, there was poor utilization of personal protective devices. Hence, we recommend improved awareness and strict use of protective gears. We recommend legislative prescription of adherence to use of sunscreens and dust - proof hoods that will reduce the exposure of street sweepers to multiple occupational hazards. We also suggest that outdoor sweeping could be scheduled to take place during the evening hours when the exposure to sunlight is minimal.

\section{Limitation Of Study}

It was not possible, during this study, to standardize the exposure to dust in both groups. However, both groups are involved in sweeping, which raises dust.

\section{Conclusion}

This study showed a dry eye disease prevalence of $27.8 \%$ among street sweepers and office cleaners in Calabar metropolis. Street sweepers had higher odds of developing dry eye disease compared to office cleaners. This highlights the role of exposure to multiple environmental irritants in developing dry eye disease. We recommend improved awareness and strict use of protective gears.

\section{Abbreviations}

DED

Dry eye disease

OSDI

Ocular surface disease index 
TBUT

Tear break up time

CUDA

Calabar Urban Development Authority

\section{Declarations}

\section{Ethics approval and consent to participate}

Ethical approval for this study was obtained from the Human Research and Ethics Committee (HREC) of the University of Calabar Teaching Hospital

\section{Consent from participants}

Written consent to participate was obtained from participants who were enrolled in the study.

\section{Competing interests}

No relevant conflict of interest declared

\section{Funding}

No funding was received for this study

\section{Authors' contributions}

E. C. I. Was the principal investigator, participated in the design and execution of the project, approved the final manuscript.

E. B. A. Supervised the study, involved in the design of the study and approved the final manuscript.

E. C. P. Conceptualized the study, participated in the execution of the study and the preparation of the final manuscript.

A. J. Supervised the study, involved in the design of the study and approved the final manuscript All authors have read and approved the manuscript.

\section{Acknowledgements}

None

\section{Availability of data and material}

We are available for database repository 


\section{References}

1. Tourino R, Lopez-Valladare M, Ares TR. Ocular surface tumors. In: Benitez-del -Castillo J, Lemp MA, editors. Ocular surface disease. London, St Louis, Panama City, New Delhi: JP Medical Ltd; 2013:81

2. Sangwan VS, Tseng SCG. New perspective in ocular surface disorders. An integrated approach for diagnosis and management. Curr Ophthalmol. 2001;49(3):153-68.

3. Gipson IK. The Ocular Surface: The Challenge to Enable and Protect Vision. Invest Ophthalmol. 2007;48(10):4390-4398.

4. Omoti A., Edema O, Akinsola F, Aigbotsua P. Non-traumatic Ocular Findings in Industrial Technical Workers in Delta State, Nigeria. Middle East Afr J Ophthalmol. 2009;16(1):25-28

5. Nichols KK, Bacharach J, Holland E, Kislan T, Shettle L, Lunacsek O, et al. Impact of dry eye disease on work productivity, and patients' satisfaction with Over-the-Counter dry eye treatments. Investig Ophthalmol Vis Sci. 2016;57(7):2975-2982.

6. Qihua L, Ling G, Li M, Liangcheng W, Jianjiang X, Jiaxu H, et al. Comparison on the vision-related quality of life between outpatients and general population with dry eye syndrome. Acta Ophthalmol.2014;92:124-132.

7. Lemp MA, Baudouin C, Baum J, Laibson P. DEWS Definition and Classification The Definition and Classification of Dry Eye Disease. Ocul Surf. 2007;5(2):75-92.

8. Asbell PA, Lemp MA. Dry Eye Disease. The clinician's guide to diagnosis and treatment. New York: Thieme;2007;2:1-23

9. Onwubiko S .Dry eye disease: Prevalence, distribution and determinants in a hospital-based population. Contact Lens Anterior Eye. 2013; 37(3):157-161

10. Bazeer $S$ et al. The relationship between occupation and dry eye: Ocul Surf. 2019;17(3):484-90

11. Se Ji, J., Jodhbir, M. \& Louis, T. The ocular surface: Effects of environmental pollution on the ocular surface. J. Rev. Lab. Sci. Clin. Sci. Clin. Pract. 2018;03:001

12. Bhatnagar, K. R., Sapovadia, A., Gupta, D., Kumar, P. \& Jasani, H. Dry eye syndrome: A rising occupational hazard in tropical countries. Med. J. 2017;7: 13-18.

13. Njinaka I, Uhumwangho OM, Omolabake T Edema, Dawodu OA, Omoti A. A Comparison Study of Conjunctiva Disorders in Technical and Administrative Sawmill Workers in Nigeria. Malaysian J Med Sci. 2011;18(3):43-8.

14. Shah S, Jani H. Prevalence and associated factors of dry eyes: Our experience in patients above 40 years of age at a Tertiary Care Centre. Oman J Ophthalmol. 2015;8(3):151 150.

15. Khurana AK, Choudhary R, Ahluwalia K, Gupta S. Hospital epidemiology of dry eyes. Indian J Ophthalmology. 1991;39:55-8.

16. McCarty, C.A., Bansal AK, Livingstone, P.M. et al. The Epidemiology of Dry Eye in Melbourne, Australia. Ophthalmology, 105, 1114-1119. Ophthalmology. 1998;105:1114-1119. 
17. Olaniyan SI, Fasina O, Bekibele CO, Ogundipe AO. Dry eye disease in an adult population in SouthWest Nigeria. Contact Lens Anterior Eye, British Contact Lens Association; 2016;39(5):359-64.

18. Etim BA, Echieh Cl, Echieh, CP, Ajewole J, Oyeniyi T. Awareness and Practice of Ocular Health Safety among Street Sweepers in Calabar, South-South, Nigeria. Nig J Med. 2019;28(3):281-86

\section{Tables}

Table 1: Socio-demographic characteristics of street sweepers and office cleaners in the study of dry eye disease amongst outdoor street sweepers and indoor office cleaners.

\begin{tabular}{|c|c|c|c|c|}
\hline Variables & $\begin{array}{l}\text { Street Sweepers } \\
(n=115) \\
\text { Freq. }(\%)\end{array}$ & $\begin{array}{l}\begin{array}{l}\text { Office } \\
\text { Cleaners } \\
(\mathbf{n}=115)\end{array} \\
\text { Freq. }(\%)\end{array}$ & $\begin{array}{l}\text { Total } \\
(\mathrm{N}=230) \\
\text { Freq. }(\%)\end{array}$ & p-value \\
\hline \multicolumn{5}{|l|}{ Age (years) } \\
\hline$<=20$ & $1(0.9)$ & $1(0.9)$ & $2(0.9)$ & 0.267 \\
\hline $21-30$ & $14(12.2)$ & $21(18.3)$ & $35(15.2)$ & \\
\hline $31-40$ & $44(38.3)$ & $37(32.2)$ & $81(35.2)$ & \\
\hline $41-50$ & $34(29.6)$ & $38(33.0)$ & $72(31.3)$ & \\
\hline $51-60$ & $19(16.5)$ & $18(15.7)$ & $37(16.0)$ & \\
\hline$>60$ & $3(2.6)$ & $0(0.0)$ & $3(1.3)$ & \\
\hline Mean Age \pm SD & $41.78 \pm 10.39$ & $40.26 \pm 9.46$ & $40.96 \pm 9.8$ & 0.155 \\
\hline \multicolumn{5}{|l|}{ Sex } \\
\hline Male & $3(2.6)$ & $12(10.4)$ & $15(6.5)$ & $0.016^{*}$ \\
\hline Female & $112(97.4)$ & $103(89.6)$ & $215(93.5)$ & \\
\hline \multicolumn{5}{|c|}{ Level of education } \\
\hline None & $3(2.6)$ & $1(0.9)$ & $4(1.7)$ & $<0.047 *$ \\
\hline Primary & $40(34.8)$ & $29(25.2)$ & $69(30.0)$ & \\
\hline Secondary & $57(49.6)$ & $55(47.8)$ & $112(48.7$ & \\
\hline Tertiary & $15(13.0)$ & $30(26.1)$ & $45(19.6)$ & \\
\hline \multicolumn{5}{|c|}{$\begin{array}{l}\text { Duration of years } \\
\text { on the job }\end{array}$} \\
\hline $1-5$ years & $46(40.0)$ & $45(39.1)$ & $93(38.60)$ & $<0.001 *$ \\
\hline $6-10$ years & $31(27.0$ & $32(27.8)$ & $69(28.6)$ & \\
\hline $11-15$ years & $24(20.9)$ & $9(7.8)$ & $35(14.5)$ & \\
\hline $16-20$ years & $13(11.3)$ & $10(8.7)$ & $25(10.0)$ & \\
\hline $21-25$ years & $0(0)$ & $5(4.3)$ & & \\
\hline 26-30years & $1(0.9)$ & $9(7.8)$ & & \\
\hline$>30$ years & $0(0.0)$ & $5(4.3)$ & $21(8.3)$ & \\
\hline
\end{tabular}

Table 2. Association of Dry eye with study variables. 


\begin{tabular}{|c|c|c|c|c|c|c|c|c|}
\hline \multirow[t]{2}{*}{ Variable } & \multicolumn{2}{|c|}{ Dry Eye disease present } & \multicolumn{2}{|c|}{$\begin{array}{l}\text { Dry Eye disease } \\
\text { absent }\end{array}$} & \multicolumn{2}{|l|}{ Total } & \multirow[t]{2}{*}{ Chi square } & \multirow[t]{2}{*}{ p-value } \\
\hline & $\mathrm{N}$ & $(\%)$ & $\mathrm{N}$ & $(\%)$ & $\mathrm{n}$ & $(\%)$ & & \\
\hline \multicolumn{9}{|l|}{ Age of Respondents (years) } \\
\hline$<=20$ & 0 & 0 & 2 & 100 & 2 & 100 & 31.335 & $0.000 *$ \\
\hline $21-30$ & 3 & 8.6 & 32 & 91.4 & 35 & 100 & & \\
\hline $31-40$ & 16 & 19.8 & 65 & 80.2 & 81 & 100 & & \\
\hline $41-50$ & 22 & 30.6 & 50 & 69.4 & 72 & 100 & & \\
\hline $51-60$ & 20 & 54.1 & 17 & 45.9 & 37 & 100 & & \\
\hline$>60$ & 3 & 100 & 0 & 0.0 & 3 & 100 & & \\
\hline \multicolumn{9}{|c|}{ Duration of work on the present job (years) } \\
\hline $1-5$ & 19 & 20.9 & 72 & 79.1 & 91 & 100 & 5.285 & 0.071 \\
\hline $6-10$ & 17 & 27.0 & 46 & 73.0 & 63 & 100 & & \\
\hline$>=11$ & 28 & 36.8 & 48 & 63.2 & 76 & 100 & & \\
\hline \multicolumn{9}{|l|}{ Group of Respondents } \\
\hline Outdoor Street sweepers & 41 & 35.7 & 74 & 64.3 & 115 & 100 & 7.014 & $0.008^{*}$ \\
\hline Indoor office cleaners & 23 & 20.0 & 92 & 80.0 & 115 & 100 & & \\
\hline
\end{tabular}

Table 3. Logistic regression analysis showing association of various factors with the occurrence of dry eye disease.

\begin{tabular}{llll}
\hline Variable & Odds ratio & $95 \%$ confidence Interval & p-value \\
\hline Study Group & & & \\
\hline Office cleaners & 1 & & \\
\hline Street sweepers & 2.085 & $1.106-3.929$ & $0.023^{*}$ \\
\hline Age of respondents & 1.092 & $1.054-1.132$ & $0.000^{*}$ \\
& & & \\
\hline
\end{tabular}

* Statistically significant

$\mathrm{p}<0.05$

Table 4. Distribution of ocular complaints among workers. 


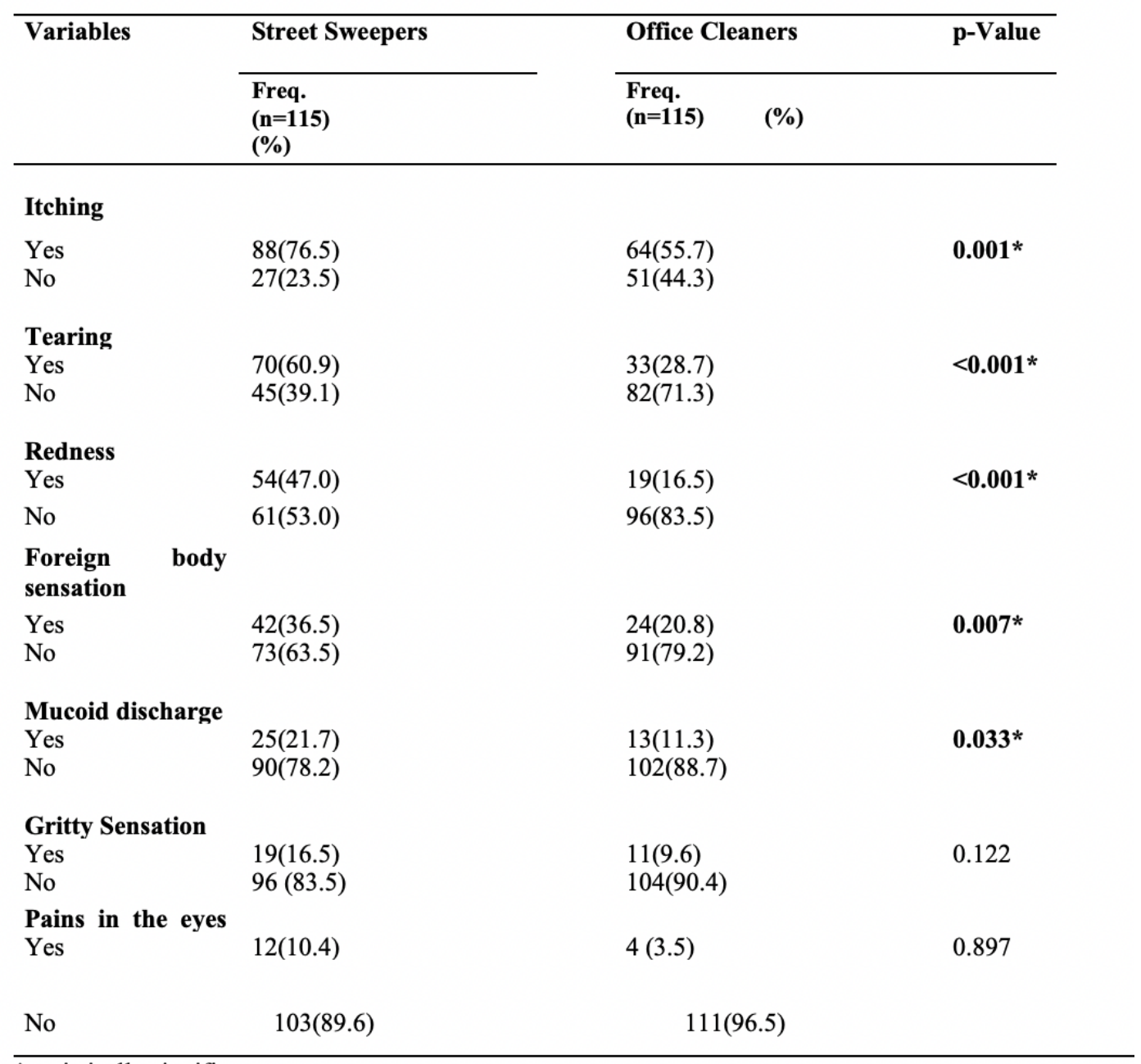

*statistically significant

$\mathrm{P}<0.05$

Figures 


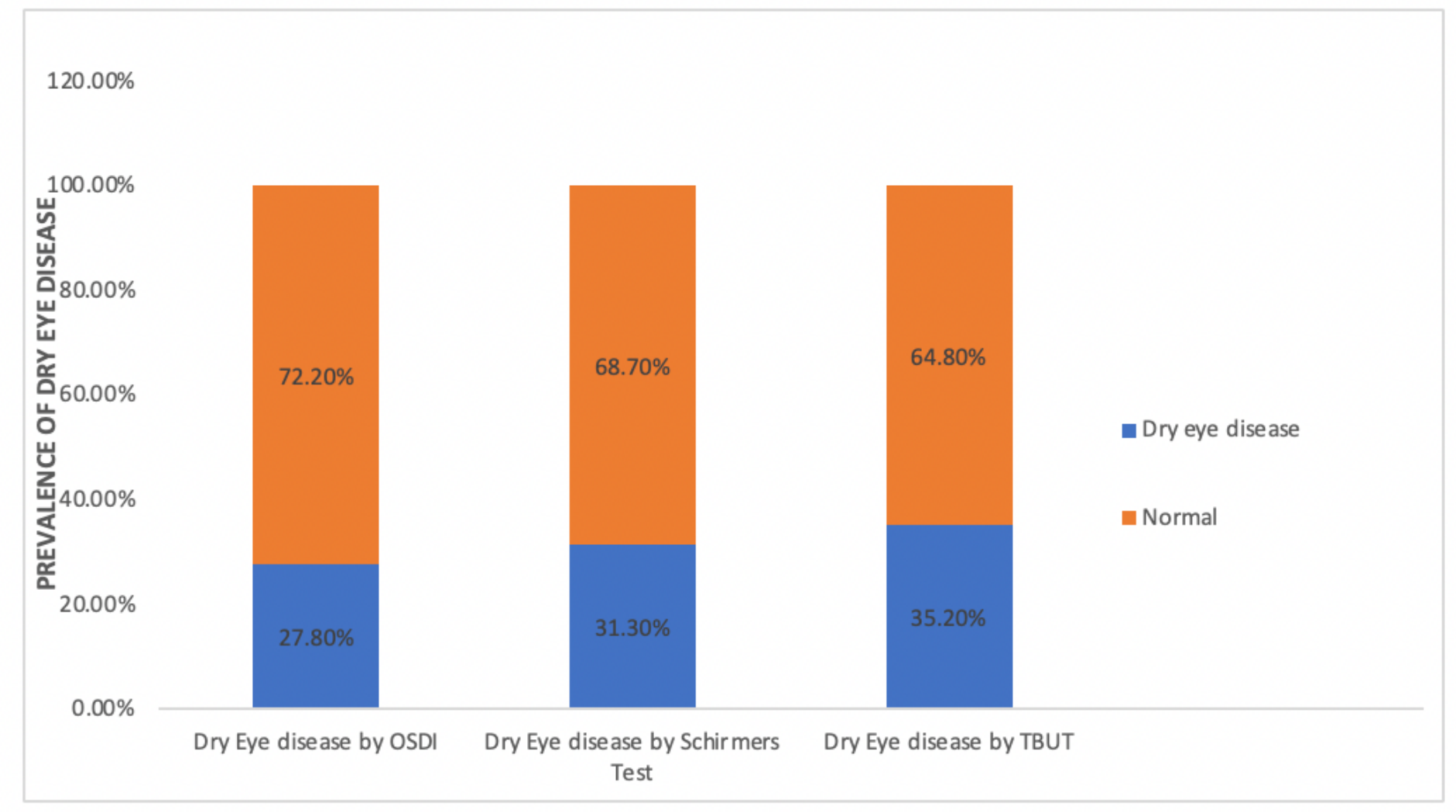

\section{Figure 1}

Bar chart showing the prevalence of dry eye disease using the OSDI, Schirmer's test 1 and Tear break up time. (TBUT) respectively. 


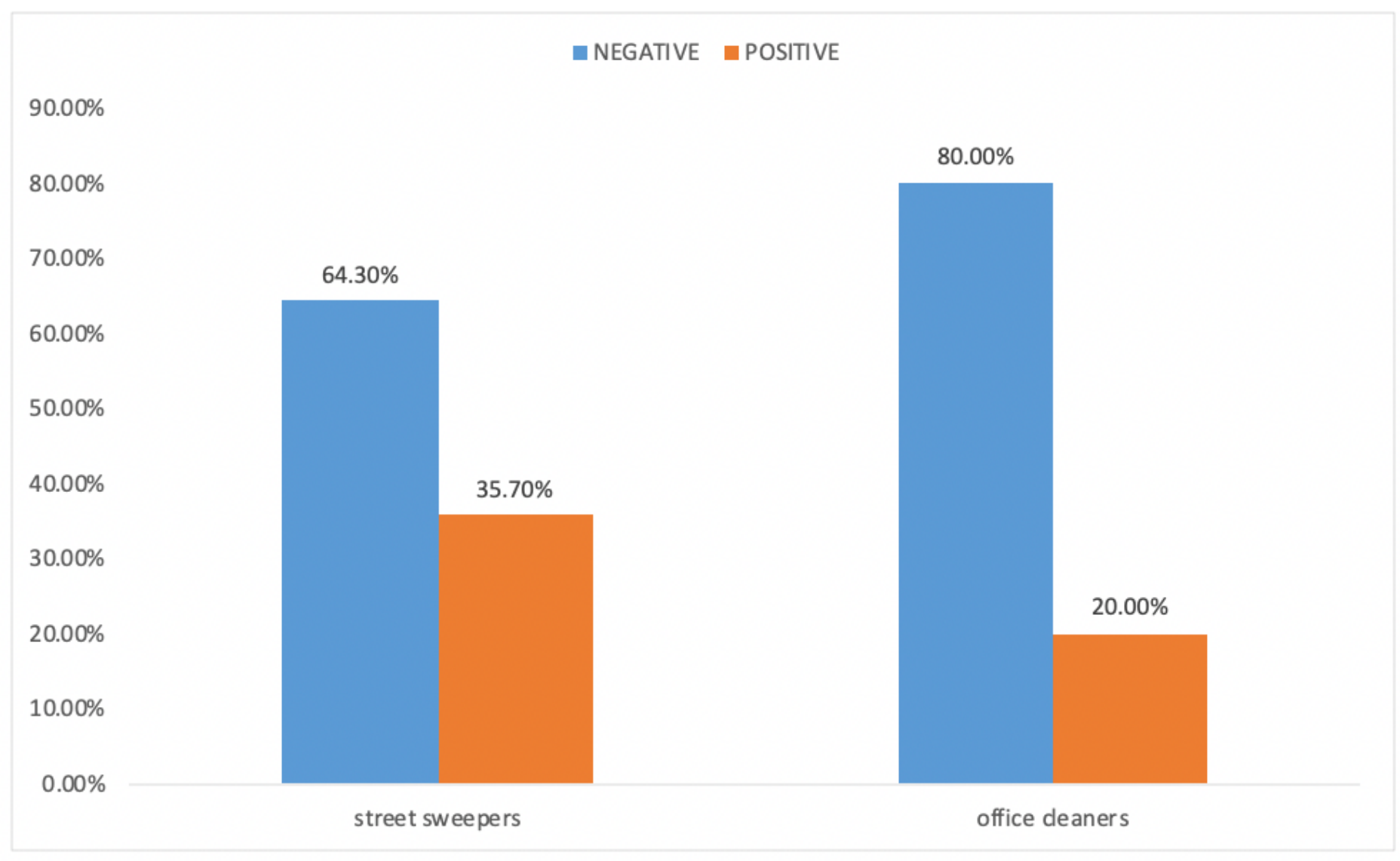

Figure 2

Bar chart comparing the OSDI Scores among street sweepers and office cleaners 


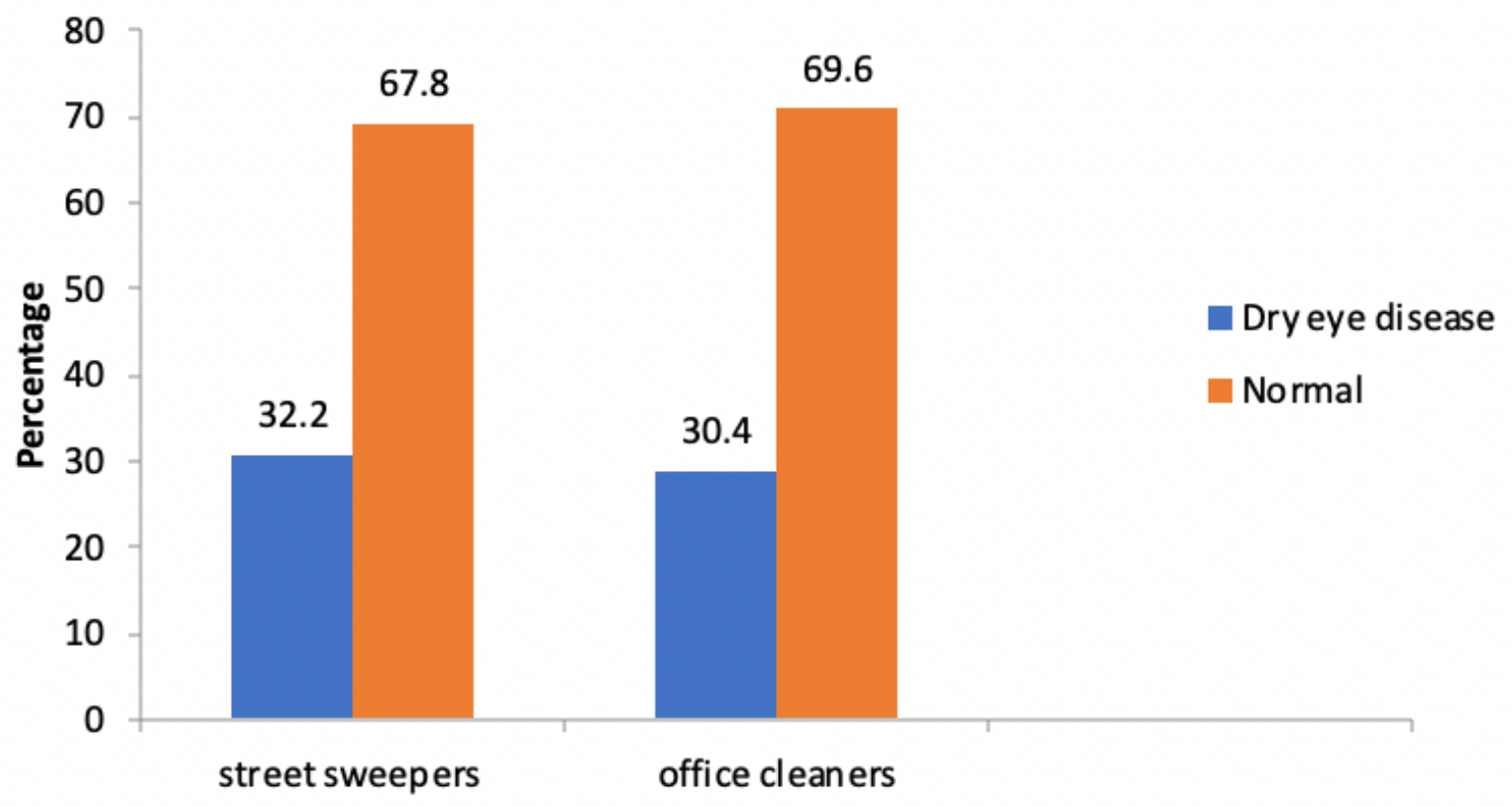

Figure 3

Bar chart comparing the prevalence of dry eye disease among street sweepers and office cleaners using Schirmer's test. 


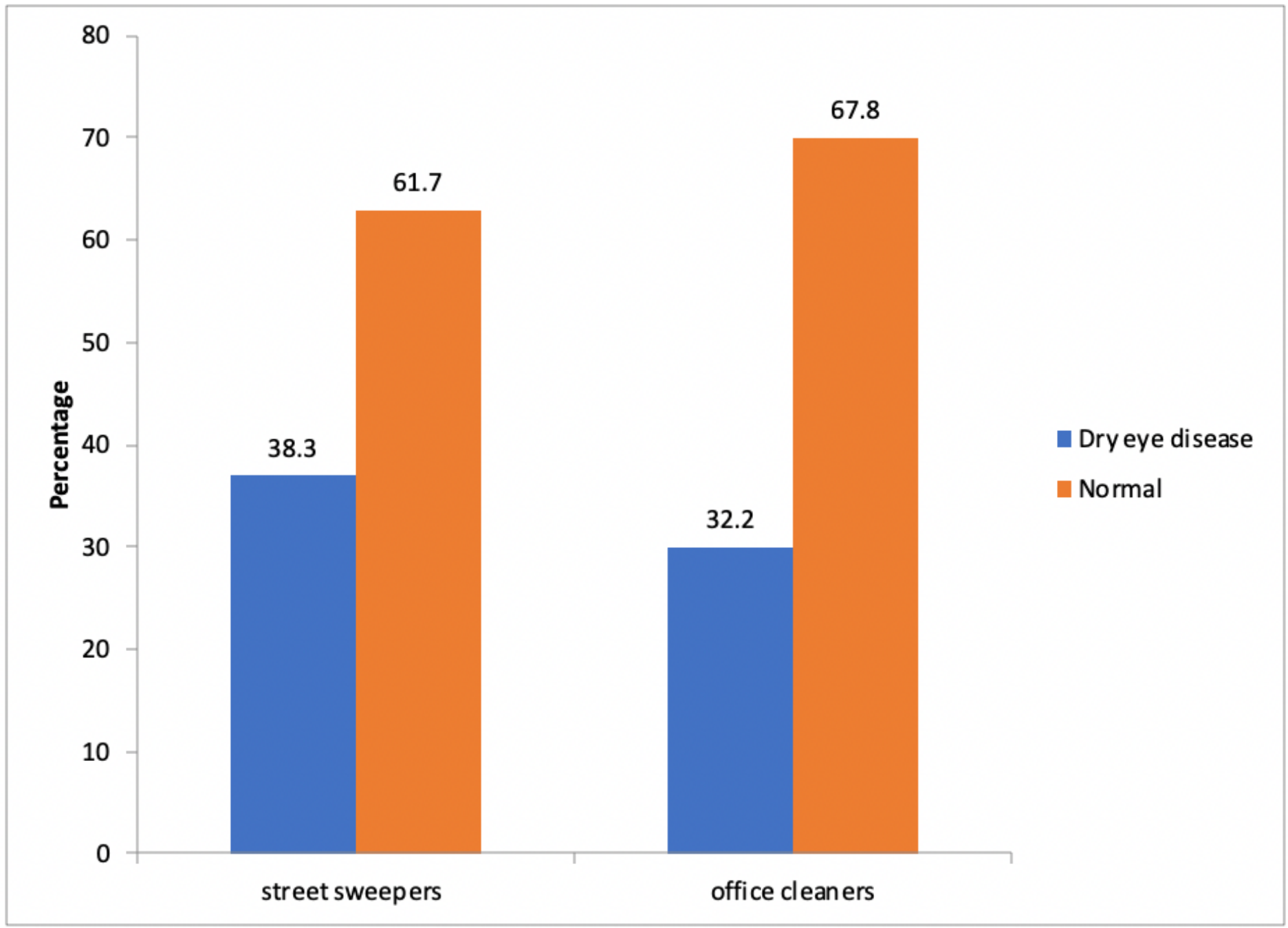

Figure 4

Bar chart comparing the prevalence of dry eyes by TBUT in street sweepers and office cleaners.

\section{Supplementary Files}

This is a list of supplementary files associated with this preprint. Click to download.

- QUESTIONNAIRE.docx 